\title{
Erratum to: Breeding opportunities for early, free-threshing and semi-dwarf Triticum monococcum $\mathrm{L}$.
}

\author{
N. Watanabe
}

Published online: 21 August 2017

(C) Springer Science+Business Media B.V. 2017

\section{Erratum to: Euphytica (2017) 213:201 DOI 10.1007/s10681-017-1987-0}

The publisher sincerely apologizes that due to an unfortunate turn of events during article processing erroneous text has been inserted in the article at the end of the Introduction on the second page, the lines beginning with "Kindly check and confirm......" to the end of the paragraph, accidentally contain Authors Queries, instructions from the editor to the author, and should not be there at all. Therefore the following lines should be disregarded entirely as part of the article by the reader.
The online version of the original article can be found under doi:10.1007/s10681-017-1987-0.

N. Watanabe $(\square)$

College of Agriculture, Ibaraki University, 3-21-1 Chuo,

Ami, Inashiki, Ibaraki 300-0393, Japan

e-mail: watnb@tulip.sannet.ne.jp

N. Watanabe

The Little Nursery, 1152 Ina, Toride,

Ibaraki-Pref 302-0026, Japan
"Kindly check and confirm whether the corresponding author affiliation is correctly identified and amend if necessary. The corresponding author affiliation is correctly identified. Please check and confirm Tables 3 and 5 layout and amend if necessary. I checked the layout of Table 3 and Table 5, and accepted them. Please pay attention for the accession name PI 418587, CItr 17652 and CItr 17654. The "," such as "418,587" was not necessary. There were a lot of mistakes in the text and Tables. In Table 4, the correction from " 2 analysis" to " $\chi^{2}$ analysis" was not successful. Please help me to correct it." 